\title{
Carlo G. Lacaita, Enzo R. Laforgia, Luigi Ambrosoli e la storia d'Italia. Studi e testimonianze
}

Milan, Franco Angeli ed, 2012, 232 p.

\section{Michel Ostenc}

\section{(2) OpenEdition}

\section{Journals}

Édition électronique

URL : http://journals.openedition.org/assr/26474

DOI : $10.4000 /$ assr.26474

ISSN : $1777-5825$

Éditeur

Éditions de l'EHESS

Édition imprimée

Date de publication : 31 décembre 2014

Pagination : 232

ISBN : 978-2-7132-2467-6

ISSN : 0335-5985

\section{Référence électronique}

Michel Ostenc, «Carlo G. Lacaita, Enzo R. Laforgia, Luigi Ambrosoli e la storia d'Italia. Studi e

testimonianze », Archives de sciences sociales des religions [En ligne], 168 | 2014, mis en ligne le 30 avril 2015, consulté le 01 mai 2019. URL : http://journals.openedition.org/assr/26474 ; DOI : 10.4000/ assr.26474

Ce document a été généré automatiquement le 1 mai 2019.

(C) Archives de sciences sociales des religions 


\section{Carlo G. Lacaita, Enzo R. Laforgia, Luigi Ambrosoli e la storia d'Italia. Studi e testimonianze}

Milan, Franco Angeli ed, 2012, 232 p.

Michel Ostenc

\section{RÉFÉRENCE}

Carlo G. Lacaita,, Enzo R. Laforgia, Luigi Ambrosoli e la storia d'Italia. Studi e testimonianze, Milan, Franco Angeli ed, 2012, 232 p. 
1 Cet ouvrage collectif consacré à l'œuvre historique de Luigi Ambrosoli comporte d'intéressantes études sur le catholicisme en Italie. Hostiles à la formation d'un État national qu'ils considéraient comme l'héritier de la Révolution française, les catholiques italiens mirent au point pendant les premiers temps de l'Unité une stratégie de pénétration de la société. Ils opposèrent leur enracinement séculaire dans la société de la péninsule à un État libéral né d'un Risorgimento bourgeois étranger aux masses populaires. Les positions intransigeantes de Pie IX conduisirent le Saint-Siège à rompre tout contact avec la politique italienne. Ambrosoli estimait que l'Église allait payer cet isolement non seulement de la perte de son pouvoir temporel mais aussi par contre

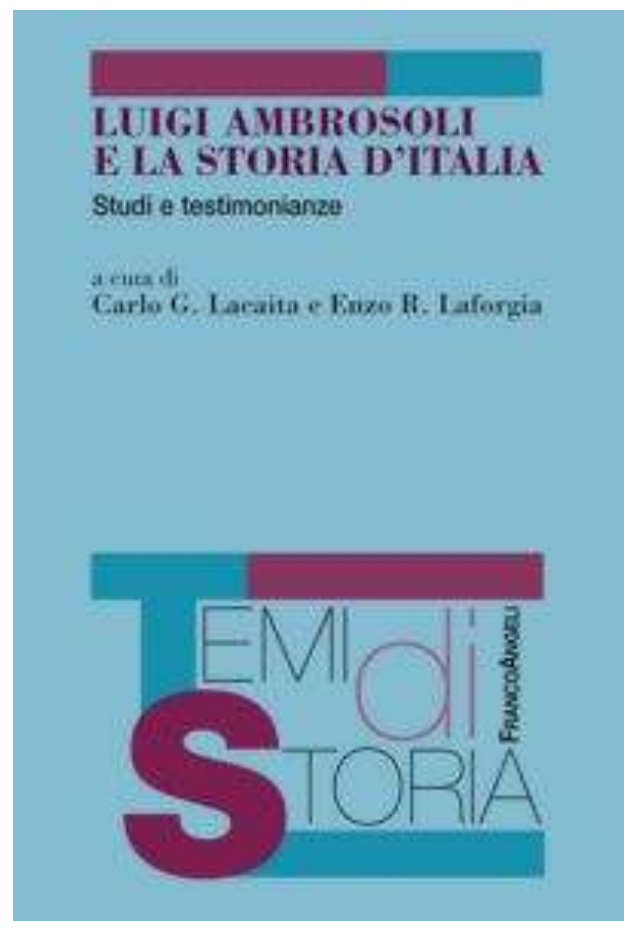
coup d'un recul de son pouvoir spirituel. L'État libéral italien n'en rencontrait pas moins sur sa route un adversaire qui lui suscitait des difficultés internationales et l'hostilité interne des catholiques intransigeants.

2 La principale organisation de ces catholiques irréductibles fut l'Opera dei Congressi, née dès juin 1874. Dans une première phase, ce mouvement considéra l'éducation comme une priorité au point de déroger à la consigne pontificale du «non expedit » pour préconiser une participation des catholiques aux élections locales afin de ne pas abandonner à ses adversaires une école publique gérée par les communes. Avec les lois du ministre Michele Coppino (1877) instaurant l'obligation scolaire, l'instruction religieuse était remplacée par un enseignement des Devoirs de l'Homme et du citoyen, même si diverses interprétations permirent de la considérer comme facultative. Les catholiques italiens furent alors incités à fonder leurs propres écoles en s'appuyant dans un premier temps sur les oratoires de Jean Bosco. L'Opera dei Congressi atteignit son plein essor après 1887, mettant l'accent sur l'action sociale et un corporatisme catholique dans la perspective ouverte par «Rerum Novarum». Elle critiquait vivement les écoles publiques où elle défendait vigoureusement l'instruction religieuse et revendiquait la liberté de l'enseignement. Son principal animateur Giuseppe Tovini regroupait les enseignants catholiques dans une ligue et fondait les périodiques «Fede e Scuola » et « Scuola italiana moderna » pour les aider sur le plan pédagogique et didactique. À l'aube du xxe siècle, des divisions profondes se manifestèrent au sein de l'Opera dei Congressi. Les intransigeants persistaient dans leur opposition aux institutions libérales du «pays légal » et menaient une action de défense sociale et religieuse auprès du "pays réel». Les plus jeunes regroupés autour de Romulo Murri entendaient transformer l'Opera dei Congressi en parti politique démocrate-chrétien. Pie X mettra fin à l'Opera dei Congressi en 1903. La pensée de Murri, suspendu « a divinis » en 1907 et excommunié en 1909, suscite toujours une certaine perplexité dans l'histoire officielle du monde catholique italien. Luigi Ambrosoli ne voyait pas dans le programme de Murri un simple expédient pour 
combattre le socialisme, ni un prétexte pour relancer une politique cléricale intransigeante. Comme l'historien Pietro Scoppola, il insistait sur l'influence de Murri sur le futur fondateur du Parti populaire italien (PPI) le prêtre sicilien Luigi Sturzo.

3 L'histoire du PPI retenait l'attention d'Ambrosoli qui s'interrogeait sur «l'unité politique des catholiques». Cette théorie avait permis aux tendances cléricales et réactionnaires d'adhérer au parti de Sturzo, l'empêchant de représenter une démocratie chrétienne authentique comme l'auraient souhaité ses fondateurs. La personnalité de Luigi Sturzo restait au centre des débats. Selon Carlo Iemolo, l'échec du PPI était lié au mysticisme de Sturzo qui rêvait d'un vaste mouvement catholique et social à vocation majoritaire. Pietro Scoppola estimait que le prêtre sicilien s'était trop consacré à l'action parlementaire à une époque (1919-1924) où la crise politique de l'État libéral privait cette institution de toute valeur. Sturzo envisageait une moralisation de la vie politique qui ne visait pas seulement le monde libéral compromis dans les manœuvres du « giolittisme », mais aussi l'État national. Il ne semblait pas réaliser la valeur de la Nation comme élément de base du monde moderne. Le "peuple» de Sturzo ne pouvait s'identifier à la «nation» italienne. Ambrosoli s'en tenait à des considérations politiques et ne cachait pas sa perplexité devant les positions de Sturzo, toujours hostiles à une ouverture vers le socialisme. Par contre, Ambrosoli observait la prudence de Sturzo devant les concessions faites à l'Église par la réforme scolaire de 1923 qui abandonnait la laïcité de l'État, concédait d'amples possibilités aux établissements privés et reconnaissait le rôle fondamental de l'enseignement de la religion à l'école primaire. Le prêtre sicilien considérait qu'il s'agissait de dispositions cléricales et il ne ménageait pas ses critiques sur la façon dont le fascisme les avait dénaturées.

Les positions d'Ambrosoli concernèrent ensuite les propositions catholiques des années 1970 concernant la révision du concordat. L'historien les rejetait en estimant qu'elles se contentaient de remplacer l'enseignement de la doctrine chrétienne, fondement et couronnement de l'instruction publique italienne selon les dispositions concordataires, par une référence au christianisme comme partie intégrante du patrimoine historique du peuple italien. Le problème civil sera partiellement résolu par le referendum sur le divorce de 1974, mais le fond du débat portait toujours sur l'enseignement de la religion à l'école publique. Ambrosoli s'opposera encore à tout financement public des établissements privés dans le cadre de conventions, le rôle de l'école d'État étant d'assurer une confrontation équitable entre tous les courants de pensée. Les jugements de l'historien sur le mouvement catholique italien rejoignaient ses préoccupations idéologiques. Il avait consacré d'autres études à la pensée de Mazzini et de Carlo Cattaneo, s'efforçant de dessiner les contours spécifiques d'un courant laïque italien authentique. Tel est le fondement même de la démarche historique de Luigi Ambrosoli. 